https://doi.org/10.48009/1_iis_2013_315-321

Issues in Information Systems

Volume 14, Issue 1, pp.315-321, 2013

\title{
COULD AN INTERACTIVE AND TOTAL IMMERSIVE DEVICE WITH HMD IMPROVE MEMORY AND GIVE THE PRESENCE SENSATION?
}

\author{
Evelyne Lombardo, Euromed/Kedge, and LSIS, CNRS, evelyne.lombardo@euromed-management.com \\ SergeAgostinelli, LSIS, CNRS, serge.agostinelli@univ-amu.fr \\ Marielle Metge, LSIS, CNRS, marielle.metge@univ-tln.fr
}

\begin{abstract}
We studied two interactive (functional and intentional interactivity) and immersive (technical and psychological immersion) devices with a personal $3 D$ viewer $\left(360^{\circ}\right.$ vision and environmentally ego-centered) and their effects on the explicit long-term memories of the subjects (4 groups of 30 students for a total of 120 subjects) (2007 and 2012). We have tested memory, communication and feeling of presence in our virtual environment with a canonic test of presence (Witmer and Singer, 1998). In our first experiment (2007), the results showed that there was no improvement in mnemonic performances compared with other types of media (PowerPoint classes without taking notes, with the taking of notes and a lecture class with no other medium). Our second experiment (2012) used a total-immersion device with the ability for the subjects to share their emotions and sensations through a network, results in progress). This article is a reflection on immersion and the presence sensation in a virtual environment in these $3 D$ devices.
\end{abstract}

Keywords: immersion, sensation of presence, HMD (Head Mounted Display) and virtual imagery.

\section{INTRODUCTION}

\section{Immerson And The Presence Sensation In A Virtual Environment}

The presence sensation in a virtual environment is sometimes mixed with that of immersion, but actually refers to the psychological side, whereas the notion of immersion refers more to the technological side. The notion of "presence... is the psychological sensation of being in an environment whose technological base is the immersion" (Slater and al., 2001). Moreover, the immersive solution system does not necessarily include the presence sensation for the user (Slater and Usoh, 1993, Slater and al., 2001). Indeed, the presence sensation is not characteristic of Virtual Reality and could also be associated with other media such as cinema, literature, or theater. The presence sensation can therefore appear in a non-immersive environment. In an experimental study, Shubber (1998) demonstrated the existence of a presence sensation during the playing of video games, considered as non-immersive virtual environments. The interactive aspect, user action on the environment and the action of images on their perceptions appear to be sufficient to provoke a presence sensation in the user and "the perceived image coupled with the action (is) sufficiently strong to make the player react and experience a presence sensation". The presence sensation therefore seems to be independent of the degree of immersion in the environment. In order to perceive the sensation of being present in an environment of virtual reality rather than in other media, Barfield and Hendrix (1995) distinguished "virtual" presence from presence in the physical environment: "virtual presence is generally conceived as being a subjective and hypothetical state of consciousness and implication in a non-present environment" (Barfield and Hendrix, 1995). The term telepresence is sometimes designated by some researchers as being synonymous with the presence sensation: "telepresence is defined as the experience of presence in a virtual environment..." (Steuer (1992). For Steuer, the term presence refers to the natural perceptions of an environment whereas telepresence refers to the mediatized perception of an environment. "This environment can be a nonexistent animated virtual environment that is synthesized by a computer (for example, an animated world created in a video game)" (Steuer, 1992). According to Seipel, (2003) a virtual environment is considered as total immersion when the totality of the user's senses is called upon on the one hand, while on the other hand there is total immersion of each sense (even if this total immersion is seldom attained in practice), the environment is considered as no immersive when one uses a «desktop» display (Psotka and al., 1993). These are generally computer screens. According to Slater and Usoh (2001), in an immersive environment, the users have an:

- $\quad$ egocentric view of the virtual world, that is, a view from the inside of the environment or of the phenomenon, as opposed to an

- $\quad$ exocentric view from the outside of the environment, where the user does not directly take part in the virtual world. For systems of these types, immersive technologies are used: data gloves, CAVE (Cave Automatic 


\section{Issues in Information Systems \\ Volume 14, Issue 1, pp.315-321, 2013}

Virtual Environment) or HMD (Head Mounted Display), headsets, etc. Technologies of this kind allow visual immersion of the user in a virtual environment. In virtual environments, the user's interactions are said to be subordinated to four tasks, according to Fuchs et al. (2001), as regards functional interaction. The user's four tasks are: observe the virtual world, navigate in the virtual world, act upon the virtual world, and communicate. We can therefore describe the structure of our experiment as an immersive, interactive structure, giving the sensation of presence.

\section{RESEARCH METHODOLOGY}

We created five homogeneous groups of students (18 students per group in the second year of initial training, DUT (Diplôme Universitaire Technologique) of TC (Techniques de Commercialisation, IUT: Institut Universitaire Technologique.) at the IUT of Université du Sud, in the setting of our courses in the Psycho-sociology of Organizations), ninety students were tested. The content of this course was the same in the five groups:

1. An oral, media-based course: the course was dictated but the students did not take notes.

2. A media-based course in PowerPoint alone but without note taking. The images and the diagrams were the same as those that were used in the course in synthetic images.

3. A media-based course in PowerPoint, with note taking. The images and the diagrams were the same as those that were used in the course in synthetic images.

4. A media-based course in virtual imagery and synthetic images (3D, vision headset, total immersion).

5. A control group course, the pre-test and the post-test only.

We compared the five courses on:

- - The cognitive and memorial aspects (long-term explicit memory)

- - Identifying the different types of communications

We ventured two hypotheses:

H1: A course in virtual images allows a better memorization compared with other types of media-based presentations (Auditory, PowerPoint without notes, PowerPoint with notes);

H2: the type of media-based presentation acts on the communication of course content and the students experienced the four types of media-based presentation differently.

For our first hypothesis our initial hypothesis was calling upon an increasing number of sensory modes which have made simultaneously possible the increasing performance of the long-term explicit memory of the information delivered by the didactic content (Paivio, double coding theory, 1986, and 1991; Paivio and Caspo 1969). As far as our experiment is concerned, we have tested long term / explicit memory. In fact, this is the form of memory at work when memorizing a course, even if learning brings several forms of memory into play. The result of our study showed that students did not have better memory performances in 3D virtual image course with HMD. It is the reason why we thought that these results could be explained by students' resistance to change.

Our approach combined:

1. A quantitative analysis based on hypothetical-deductive reasoning (first hypothesis) in order to analyze if an immersive 3D structure in the framework of our courses on the Psycho-sociology of Organizations would have effects on memorization and to test the sensation of presence in the course presented by means of virtual images

2. A qualitative analysis (second hypothesis) a) in order to understand how the students experienced the different communications situations across the four types of media-based presentation; and b) to study how they accepted the presence sensation.

For our first hypothesis, the differences in results obtained by the courses were calculated by variance analysis (Anova). We used a test T. of Student to test the sensation of presence in the virtual environment. The results of the Anova and the test $\mathrm{T}$. of Student are presented in this article.

For our second hypothesis, we did 18 interviews of 18 students who undertook the course in virtual images with HMD. First, we present our case study. 


\section{CASE STUDY: an immersive and interactive structure, giving the sensation of presence}

We can describe the structure of our experiment as 1) an immersive, 2) interactive structure, 3) giving the sensation of presence.

\section{A total immersive structure}

Many authors have likened this term to a technical notion, which might act on the user's senses. Cadoz (1994) asserts that immersion is "a technology, an interface technique between man and machine and does not involve the psychological state of the subject". The physical immersion of a subject in a virtual environment is performed by sensory information (sight, hearing, etc.) alone.

For Pimentel and Texeiria (1993), immersion is "the state of a participant when one or more of his senses ... is isolated from the exterior world and he no longer registers any information that does not come from the computer".

Our structure was a total immersive structure because the students had a 360 degrees vision and an egocentric view of the virtual world.

\section{An Interactive Structure}

In virtual environments, the user's interactions are said to be subordinated to four tasks, according to Fuchs et al. (2001), as regards functional interaction. The user's four tasks are to:

1) Observe the virtual world

2) Navigate in the virtual world

3) Act upon the virtual world

4) Communicate

Observing the virtual world is a stage that allows us to prepare ourselves for other actions and that is necessary for understanding the virtual world.

Navigating, acting and communicating presume an action on the user's part. The structure of our experiment can thus be considered as interactive in the sense that it allows the user to perform these four actions.

\section{A Structure Giving the Sensation of Presence in a Virtual Environment}

The feeling of being present in a virtual environment is sometimes combined with that of immersion, but it forms the psychological aspect, while the notion of immersion refers more to the technological aspect. The notion of "presence" in a virtual world is "the psychological feeling of being there in the environment, of which immersion is the technological basis" (Slater and Usoh, 2001).

For our experiment, the students were equipped with:

A HMD (Head Mounted Display, that is, a Sony Glasstron LDI-D100B ruggedized vision headset (LCD screen, Resolution 800x600, non-stereoscopic, visual field $26^{\circ}$ Horizontal, $19.6^{\circ}$ vertical, headphones with stereophonic sound - see Figure 1).

A Tracker (movement detector) Intersense intertrax ${ }^{2}$ ( 3 degrees of freedom, angular resolution: $0.02^{\circ}$, latency time 4 Ms: internal refresh rate of $256 \mathrm{~Hz}$ ), mouse buttons as navigation tools.

Software used: Unreal 2004, 3D Studio max, Actor X, PowerPoint.

The students were in total immersion, in an interactive structure giving the sensation of presence. 


\section{Issues in Information Systems}

Volume 14, Issue 1, pp.315-321, 2013

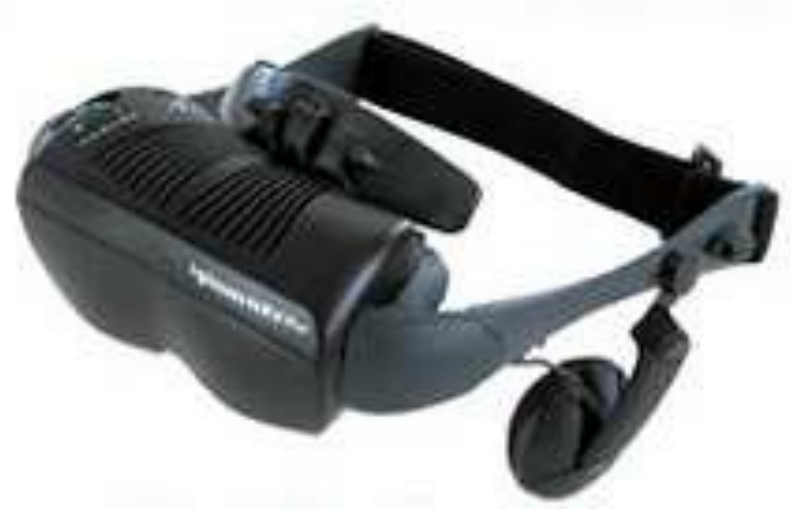

Figure 1 Head Mounted Display used for the experiment

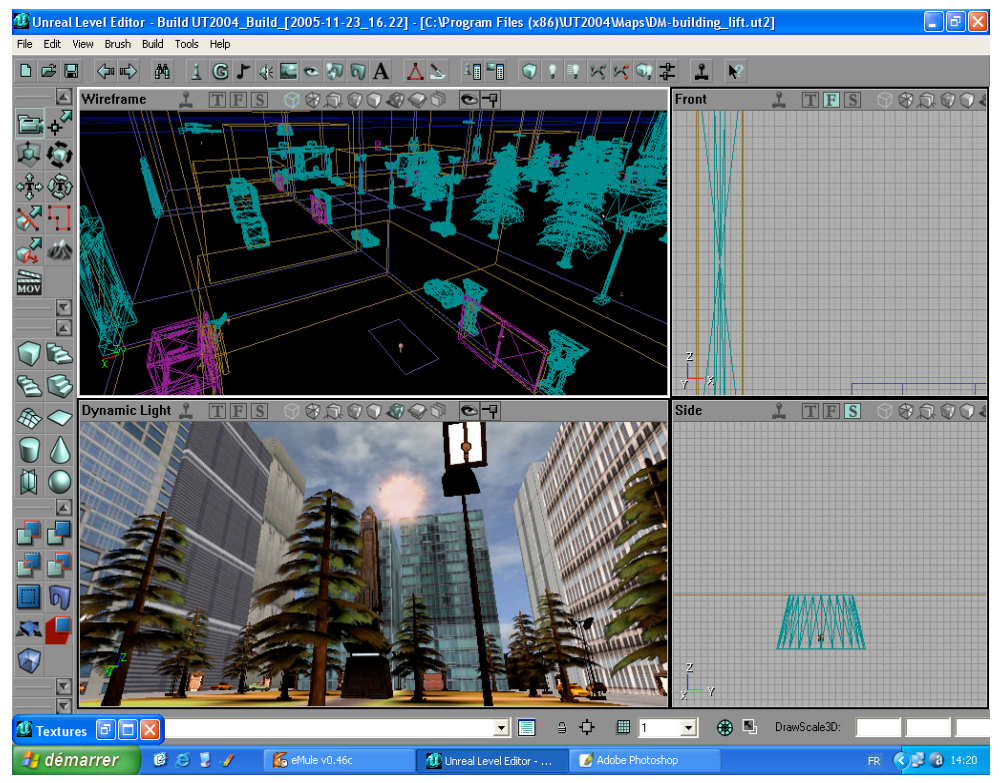

Figure 2 software solution

\section{The People Involved in the Project}

Doctor Eric Malbos, physician and neuro-psychologist, who has elaborated a system conceived within a virtual environment in order to treat patients suffering from phobias by successive habituations. He created the storyboard of the course in virtual imagery, the animations and the course in virtual imagery.

A professor of Psycho-Sociology of organization who prepared a doctorate thesis (2007) was the project leader.

A media engineering student from the University of Toulon and the South (Wallid), a specialist in synthetic images, has created, in the framework of a proficiency grant, the 3D images for the course in virtual imagery. 


\section{Issues in Information Systems}

Volume 14, Issue 1, pp.315-321, 2013

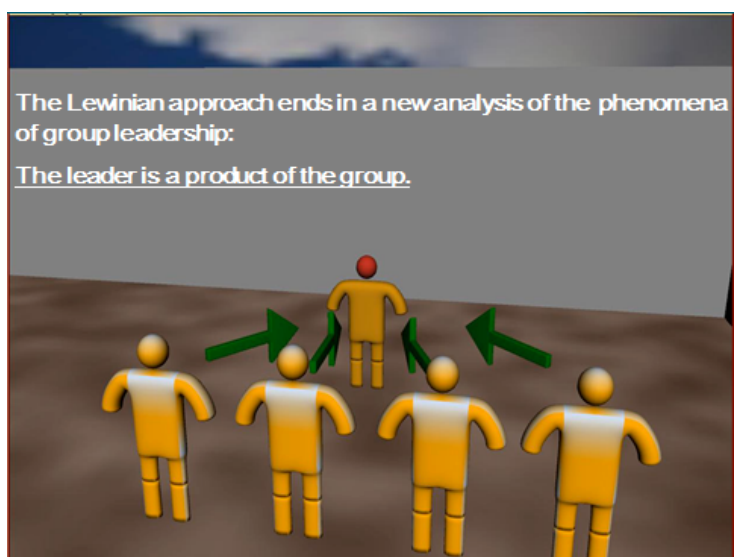

Figure 4 An example of images used for the PowerPoint and the course in virtual images

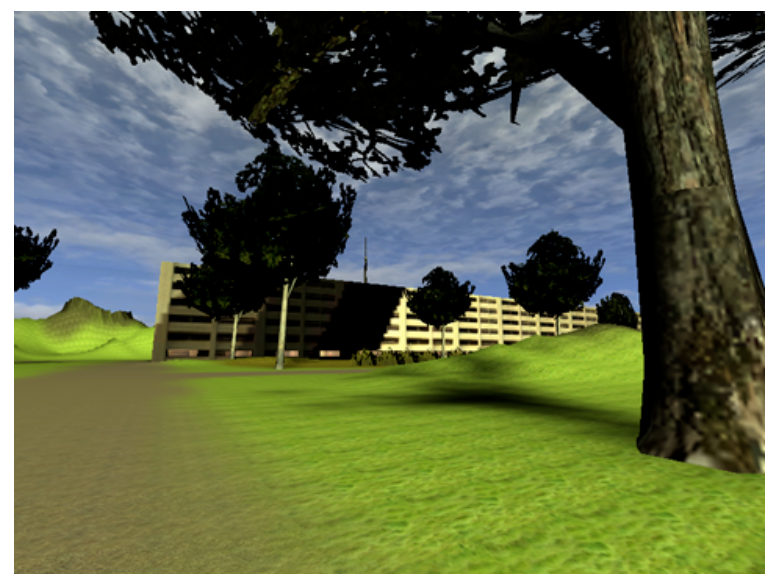

Figure 3 An example of the virtual environment:

The students had to get into the university and traverse 23 classrooms.

A way of verifying hypothesis $\mathrm{H} 1$ was to construct a quasi-experimental system that allowed us to vary the different dimensions of the Independent Variable (IV) and to create teaching structures, with each one of them corresponding to a mode of the IV that we wanted to test, that is the structure of the media-based presentation.

The IV has several modes: course 1 auditory, course 2 PowerPoint without note taking, course 3 PowerPoint with note taking, course 4 by means of virtual images in immersive 3D.

The differences in results obtained by the courses were calculated by variance analysis (Anova), and by a test T. of the Student.

\section{Anova results H1}

\section{RESULTS}

Group 3 (PowerPoint with note taking) is the one that had the clearest significant improvement in performance.

By decreasing order of performance, group 2 came next (PowerPoint without note taking), then group 4 (virtual images), then group 1 (auditory) and last came group 5 (the control group).

\section{Results of the test of presence $\mathrm{H1}$}




\section{Issues in Information Systems}

Volume 14, Issue 1, pp.315-321, 2013

The results show that the students had a feeling of presence within the virtual environment of the course in immersive 3D.

\section{Results of the qualitative treatment $\mathrm{H} 2$}

The recurrent themes in the 4 groups (auditory, PowerPoint with note taking, without note taking, and by virtual images) were the following:

Theme 1: emotional

Positive emotional dimension: original universe/ environment; innovation/social network; funny.

Negative emotional dimension: unreal; "small lab rats".

Theme 2: physical

Positive physical dimension: sensation of presence in virtual environment

Negative physical dimension: discomfort/sick ; headache

Theme 3: cognitive

Positive cognitive dimension: simulation as a help in learning; simulation as a help in understanding the reality; experiment as a source of motivation

Negative cognitive dimension: no human aspect: learning boundaries

Theme 4: intentional

Positive intentional dimension: emulation to take the course in virtual image

Negative intentional dimension: technical aspects of virtual device

\section{CONCLUSIONS}

The aim of this paper was to study two interactive, total immersive devices with a $360^{\circ}$ view of the environment and particularly their effects on memory and on the presence sensation.

The results of our study could be resumed in 2 points:

1) Our study showed that in the course in virtual imagery (total immersive device with HMD) the performance of long-term memory is no better than in the other courses. Group 3 (PowerPoint with note taking) is the one that had the clearest significant improvement in performance. And by decreasing order of performance, group 2 came next (PowerPoint without note taking), then group 4 (virtual images), then group 1 (auditory) and last came group 5 (the control group).

2) The results show that the students had a feeling of presence within the virtual environment of the course in immersive 3D. This feeling of presence is physical:

Eg: The course in virtual image has emerged as "a universe" (student 5V), a world", "virtual world" (Student 2V), "and thus we entered directly into a virtual world.

The physical immersion was felt by many students in the course virtual images, "I said through the headset and looking directly at the video, we felt really "in", like almost in the character.

"We were in the character, the main character, and it is true that I was fully integrated in this virtual world, I had returned"(Student 3V)"The sensation of moving the head, that was interesting" (Student 1V).

\section{REFERENCES}

1.Barfield, W., \& Hendrix, C. (1995). The effect of update rate on the sense of presence within virtual environments. Virtual Reality. The journal of virtual reality society, 1(1), 3-16.

2.Cadoz, C. (1994). Les réalités virtuelles (p. 125). Paris: Dominos-Flammarion.

3.Lombardo, E. (2007). Analyse communicationnelle des effets cognitifs d'un dispositif éducatif médiatisé: le cas de la médiatisation d'un cours 3D en images virtuelles immersif et interactif et ses impacts sur la mémoire explicite. Université du Sud, Toulon, Var.

4.Fuchs, P., Moreau, G., \& Papin, J.-P. (2001). Le traité de la réalité virtuelle (p. 517). Paris: Techniques Ingénieur. 5.Paivio, A. (1991). Dual coding theory: Retrospect and current status. Canadian Journal of Psychology, 45, 255- 


\section{Issues in Information Systems}

Volume 14, Issue 1, pp.315-321, 2013

287.

6.Paivio, A. (1986). Mental representations: a dual coding approach (p. 323). Oxford: Oxford University Press.

7.Paivio, A., \& Csaspo, K. (1969). Concrete images and verbal memory codes. Journal of experimental psychology, $80(2), 279-285$

8.Pimentel, K., \& Teixeira, K. (1993). La réalité virtuelle: De l'autre côté du miroir (p. 338). Paris: Addison Wesley.

9.Psotka, J., Davison, S., \& Lewis, S. (1993). Exploring Immersion in Virtual Space. Virtual Reality Systems, 1(2), $70-92$.

10.Seipel, S. (2003). Visualizations technologies. Uppsala Universitet. Retrieved March 23, 2013, from http://www.it.uu.se/edu/course/homepage/igs/ht03/lectures/igs_07_visualization_techniques.pdf

11.Shubber, Y. (1998). Les réalités virtuelles et la présence: de la conceptualisation à l'opérationnalisation. Recherches en Communication, 10, 161-185.

12.Slater, M., Linakis, V., Usoh, M., Kooper, R., \& Street, G. (2001). Immersion, presence, and performance in virtual environments: An experiment with Tri-Dimensional Chess. ACM Virtual Reality Software and Technology (VRST), 163-172.

13.Slater, M., \& Usoh, M. (1993). Presence in immersive virtual environments. Virtual Reality Annual International Symposium (pp. 90-96).

14.Steur, J. (1992). Defining virtual reality: Dimensions determining telepresence. Journal of Communication, 42(4), 73-93.

15.Witmer, B., \& Singer, M. (1998). Measuring presence in virtual environments: A presence questionnaire. Presence, 7(3), 225-240. 